Indo. J. Chem. Res., 2018, 5(2), 58-62

\title{
SINTESIS DAN KARAKTERISASI SELULOSA ASETAT (CA)
}

\section{Synthesis and Characterization of Cellulose Acetate (CA)}

\author{
Fensia Analda Souhoka*, Jolantje Latupeirissa \\ Department of Chemistry, Faculty of Matemathic and Natural Sciences, Pattimura University, \\ Jl. Ir. Putuhena No. Poka, Ambon 97233 - Indonesia \\ *Corresponding author, e-mail: fensia@fmipa.unpatti.ac.id
}

Received: Nov. 2017 Published: Jan. 2018

\begin{abstract}
Synthesis and characterization of cellulose acetate (CA) has been conducted. The cellulose used in this study is a commercial $\alpha$-cellulose in $92 \%$ content. All the CA products were analyzed by FTIR spectrometers. Determination of cellulose content was done using standart method of TAPPI T-203, while the determination of the degree of substitution (DS) was based on SNI 0444:2009 method. Conventional acetylation of cellulose was performed using glacial acetic acid, anhydride acetic acid, and sulfuric acid. The acetylation at $25^{\circ} \mathrm{C}$ for 2.5 hours gave the DS of 1.482 and at $40{ }^{\circ} \mathrm{C}$ for 5 hours gave the higher DS 2.295.
\end{abstract}

Keywords: Acetylation, cellulose, cellulose acetate, degree of substitution

\section{PENDAHULUAN}

Selulosa merupakan biopolimer alami yang sangat berlimpah di alam. Selulosa merupakan polimer rantai lurus dari ratusan hingga puluhan ribu ikatan glikosida $\beta-(1,4)$ unit D-glukosa, yang menyebabkan molekul-molekul selulosa membentuk rantai yang saling bersisian, kokoh, dan lurus (Fessenden dan Fessenden, 1999). Selulosa tidak larut dalam air dan pelarut-pelarut umum, karena memiliki ikatan hidrogen yang kuat, baik intramolekul maupun antarmolekul. Sebab itu, telah dilakukan modifikasi struktur selulosa supaya larut dalam air dan pelarut lainnya, sehingga turunannya banyak diaplikasikan dalam berbagai bidang.

Proses modifikasi selulosa dapat dilakukan dengan cara esterifikasi dan eterifikasi terhadap gugus hidroksil dari selulosa (Kamel et al., 2008). Esterifikasi selulosa dilakukan menggunakan asam asetat, asam nitrat, asam sulfat, dan asam fosfat. Selulosa trinitrat dapat digunakan sebagai smokeless gunpowder, sedangkan selulosa asetat umumnya dapat digunakan untuk beberapa jenis film dan bahan pelapis. Selulosa asetat juga dimanfaatkan dalam aplikasi kedokteran, farmakologi, perlakuan limbah, kromatografi, dan tekstil tiruan (Wang et al., 2009).

Selulosa asetat adalah selulosa yang gugus hidroksilnya diganti oleh gugus asetil. Selulosa asetat berbentuk padatan putih, tak beracun, tak berasa, dan tak berbau (SNI 0444: 2009). Selulosa asetat mempunyai nilai komersial yang tinggi karena memiliki karakteristik fisik dan optik yang baik, sehingga banyak digunakan sebagai serat untuk tekstil, filter rokok, plastik, film fotografi, lak, pelapis kertas, dan membran. Di samping itu, CA mempunyai daya tarik yang tinggi karena sifatnya yang biodegradable sehingga ramah lingkungan.

Gaol, dkk. (2013), membuat CA dari tandan kosong kelapa dengan variasi waktu asetilasi, diperoleh waktu maksimum 2,5 jam dengan DS 1,68. Dalam skala industri, CA diproduksi melalui dua cara, yaitu menggunakan asam asetat sebagai agen asetilasi sekaligus pelarut dan asam sulfat sebagai katalis, atau melalui proses metilen klorida yang menggunakan asam asetat anhidrida sebagai agen asetilasi, dan metilen klorida sebagai pelarut, serta asam sulfat sebagai katalis. Reaksi asetilasi selulosa ditunjukkan pada Gambar 1.

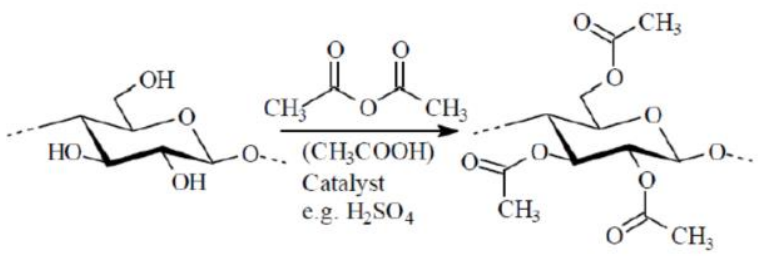

Gambar 1 Reaksi asetilasi selulosa

Pada penelitian ini dilakukan sintesis selulosa asetat melalui reaksi esterifikasi (asetilasi) 
$\alpha$-selulosa dan karakterisasi CA meliputi penentuan kadar air, kadar asetil dan DS, identifikasi gugus fungsi menggunakan spektrometer FTIR, serta sifat kelarutannya dalam pelarut air, alkohol, aseton, dan kloroform. Selulosa asetat hasil sintesis diharapkan dapat diaplikasikan sebagai bahan dasar pembuatan film atau membran pada penelitian selanjutnya.

\section{METODOLOGI}

\section{Bahan}

Bahan dasar yang digunakan dalam penelitian ini adalah $\alpha$-selulosa komersil (Sigma, CAS Number 9004-34-6). Bahan-bahan lain yang digunakan dengan kualitas pro analisis dari Merck, yaitu natrium hidroksida $(\mathrm{NaOH})$, asam asetat $\left(\mathrm{CH}_{3} \mathrm{COOH}\right)$, etanol $\left(\mathrm{C}_{2} \mathrm{H}_{5} \mathrm{OH}\right)$, asam asetat glasial $\left(\mathrm{CH}_{3} \mathrm{COOH}\right)$, natrium asetat $\left(\mathrm{CH}_{3} \mathrm{COONa}\right)$, metanol $\left(\mathrm{CH}_{3} \mathrm{OH}\right)$, asam asetat anhidrida $\left(\mathrm{CH}_{3} \mathrm{CO}\right)_{2} \mathrm{O}$, asam sulfat $\left(\mathrm{H}_{2} \mathrm{SO}_{4}\right)$, indikator $\mathrm{pp}$, asam klorida $(\mathrm{HCl})$, akuades, aseton $\left(\mathrm{CH}_{3}\right)_{2} \mathrm{CO}$, kloroform $\left(\mathrm{CHCl}_{3}\right)$, aluminium foil, $\mathrm{pH}$ universal, dan kertas saring.

\section{Alat}

Alat-alat yang digunakan dalam penelitian antara lain peralatan gelas laboratorium (pyrex), hot plate (Cimarec 1), pengaduk magnet, cawan porselin, oven (Memert), timbangan analitik (Ohaus), satu set alat titrasi, dan desikator. Instrumentasi kimia yang digunakan adalah spektrometer infra merah (FTIR, Shimadzu Prestige-21).

\section{Prosedur Kerja \\ Preparasi Sampel}

Sebelum sintesis CA dilakukan karakterisasi meliputi penentuan kadar $\alpha$-selulosa, penentuan kadar air, dan identifikasi gugus fungsi dengan spektrometer FTIR sebagai data awal.

\section{Penentuan kadar $\alpha$-selulosa}

Sebanyak 1,5 g sampel, $50 \mathrm{~mL} \mathrm{NaOH} \mathrm{7,5 \%}$ (b/v), dan $300 \mathrm{~mL}$ akuades dimasukkan ke dalam beker gelas $500 \mathrm{~mL}$ yang telah dilengkapi pengaduk magnet, kemudian diaduk dan didiamkan. Endapan yang terbentuk disaring, ditambahkan $40 \mathrm{~mL} \quad \mathrm{CH}_{3} \mathrm{COOH} \quad 10 \%$ (v/v), didiamkan selama 5 menit, dicuci menggunakan $25 \mathrm{~mL}$ etanol 96\% (v/v), diletakkan dalam cawan porselin dan dikeringkan dalam oven pada temperatur $105{ }^{\circ} \mathrm{C}$ hingga massa konstan. Serbuk selulosa kering ditimbang dan dilakukan perhitungan kadar selulosa menggunakan rumus:

Kadar selulosa $=\frac{\text { massa serbuk selulosa kering }}{\text { massa sampel kering }} \times 100 \%$

\section{Penentuan kadar air}

Cawan petri kosong dikeringkan selama 1 jam di dalam oven pada suhu $103{ }^{\circ} \mathrm{C}$, kemudian didinginkan dalam desikator, lalu ditimbang beratnya (W1). Setelah itu, ditambahkan $1 \mathrm{~g}$ sampel (W2), dikeringkan di dalam oven pada suhu $103{ }^{\circ} \mathrm{C}$ selama 2 jam, kemudian didinginkan dalam desikator, setelah itu ditimbang beratnya (W3).

Kadar air $=\frac{\text { W2-W3 }}{\text { W1 }} \times 100 \%$

\section{Identifikasi gugus fungsi dengan spektrometer FTIR}

Sampel yang akan dianalisis dipreparasi dalam bentuk pellet $\mathrm{KBr}$ dengan perbandingan $1: 100(\mathrm{~b} / \mathrm{b})$.

\section{Sintesis CA (Gaol dkk., 2013)}

Sebanyak masing-masing $2 \mathrm{~g} \alpha$-selulosa dimasukkan ke dalam labu alas bulat lalu ditambahkan $100 \mathrm{~mL}$ asam asetat glasial, kemudian diadukselama 3 jam. Selanjutnya ditambahkan masing-masing $30 \mathrm{~mL}$ asam asetat anhidrit dan 6 tetes asam sulfat pekat, kemudian campuran diaduk (dengan variasi suhu $25^{\circ} \mathrm{C} ; 2,5$ jam dan $40{ }^{\circ} \mathrm{C} ; 5$ jam). Setelah itu, ditambahkan $4,5 \mathrm{~mL}$ akuades dan $10 \mathrm{~mL}$ asam asetat glasial sambil diaduk selama 30 menit. Lalu ditambahkan $2 \mathrm{~g}$ natrium asetat sambil diaduk selama 5 menit. Campuran dicuci dengan akuades hingga netral, lalu direndam dalam metanol selama 10 menit. Hasil yang diperoleh disaring dan dikeringkan dalam oven pada suhu $50{ }^{\circ} \mathrm{C}$, kemudian digerus menjadi serbuk. Selanjutnya dilakukan analisis kadar air, kadar asetil dan DS, identifikasi gugus fungsi dengan spektrometer FTIR, serta penentuan kelarutan CA.

\section{Penentuan kadar asetil dan DS}

Sebanyak $1 \mathrm{~g}$ serbuk CA hasil sintesis dimasukkan ke dalam Erlenmeyer dan ditambahkan dengan $40 \mathrm{~mL}$ etanol $75 \%$ kemudian dipanaskan dalam penangas air pada 
suhu $55{ }^{\circ} \mathrm{C}$ selama 30 menit. Selanjutnya Erlenmeyer dikeluarkan dari penangas, kemudian ditambahkan $40 \mathrm{~mL} \mathrm{NaOH} 0,5 \mathrm{~N}$ lalu dipanaskan kembali pada suhu $55^{\circ} \mathrm{C}$ selama 30 menit. Erlenmeyer ditutup dengan alumunium foil dan didiamkan selama 72 jam. Kemudian ditambahkan 2 tetes indikator pp dan dititrasi dengan $\mathrm{HCl} 0,5 \mathrm{~N}$ (dicatat banyaknya $\mathrm{HCl}$ yang terpakai). Erlenmeyer ditutup kembali dengan alumunium foil dan didiamkan selama 24 jam. Kemudian dititrasi dengan $\mathrm{NaOH}$ 0,5 N (dicatat banyaknya $\mathrm{NaOH}$ yang terpakai). Perlakuan yang sama untuk blanko namun tanpa penambahan serbuk CA. Kadar asetil dihitung dengan rumus:

$$
\mathrm{X}=[(\mathrm{D}-\mathrm{C}) \mathrm{Na}+(\mathrm{A}-\mathrm{B}) \mathrm{Nb}] \mathrm{x}(\mathrm{F} / \mathrm{W})
$$

Sedangkan DS dihitung menggunakan rumus:

$$
\begin{aligned}
& \mathrm{DS}=\frac{162 \times\left(\frac{7 \mathrm{gsetm}}{4 \mathrm{I}}\right)}{100-\left(\frac{42}{42} \times \% \text { asetil }\right)} \times 100 \% \\
& \text { di mana: } \\
& X=\text { kadar asetil }(\%) \\
& A=\text { volume } \mathrm{NaOH} \text { yang terpakai untuk titrasi sampel }(\mathrm{mL}) \\
& B=\text { volume } \mathrm{NaOH} \text { yang terpakai untuk titrasi blanko }(\mathrm{mL}) \\
& C=\text { volume } \mathrm{HCl} \text { yang terpakai untuk titrasi sampel }(m L) \\
& D=\text { volume } \mathrm{HCl} \text { yang terpakai untuk titrasi blanko }(\mathrm{mL}) \\
& \mathrm{Na}=\text { Normalitas } \mathrm{HCl} \\
& \mathrm{Nb}=\text { Normalitas } \mathrm{NaOH} \\
& F=4,305 \\
& W=\text { Berat sampel }
\end{aligned}
$$

\section{Penentuan kelarutan CA}

Sampel CA hasil sintesis dilarutkan dalam beberapa pelarut, yaitu air, alkohol, kloroform, dan aseton kemudian dicatat hasilnya.

\section{HASIL DAN PEMBAHASAN}

Penentuan kadar $\alpha$-selulosa dan kadar air

Berdasarkan hasil perhitungan, diperoleh serbuk $\alpha$-selulosa kering sebanyak 1,38 g dengan kadar selulosa $92 \%$. Kadar air dalam $\alpha$-selulosa komersil adalah $0,358 \%$. Serbuk $\alpha$-selulosa ini digunakan untuk sintesis CA dan karakterisasi pada tahapan selanjutnya.

\section{Identifikasi gugus fungsi dengan spektrometer FTIR}

Analisis FTIR dilakukan terhadap sampel $\alpha$-selulosa dan CA hasil sintesis. Spektra yang dihasilkan dianalisis secara kualitatif untuk menginterperasikan gugus fungsi yang terkandung dalam masing-masing sampel.
Analisis dilakukan dengan cara membandingkan spektra yang diperoleh dengan hasil penelitian sebelumnya, seperti disajikan pada Tabel 1 . Souhoka (2013), telah melakukan analisis FTIR $\alpha$-selulosa hasil isolasi dari limbah sagu.

Tabel 1. Perbandingan hasil analisis spektra FTIR $\alpha$ selulosa dengan yang dilaporkan oleh Souhoka (2013)

\begin{tabular}{ccc}
\hline \multicolumn{2}{c}{ Bilangan Gelombang $\left(\mathbf{c m}^{-\mathbf{1}}\right)$} & \multirow{2}{*}{ Keterangan } \\
\cline { 1 - 2 } Eksperimen & Souhoka $(\mathbf{2 0 1 3})$ & \\
\hline $3394-3332$ & 3448 & $-\mathrm{OH}$ \\
2887 & 2931 & $\mathrm{C}_{\mathrm{sp} 3}-\mathrm{H}$ \\
1658 & 1635 & H-O-H (air terserap) \\
1433 & 1427 & $-\mathrm{CH}_{2}-$ \\
1336 & 1373 & $>\mathrm{CH}-$ \\
1242 & 1242 & $\mathrm{C}-\mathrm{O}$ eter \\
1153 & 1157 & C-O-C eter \\
1045 & 1026 & $\mathrm{C}-\mathrm{O}$ alkohol \\
898 & 856 & Ikatan $\beta$-glikosida \\
\hline
\end{tabular}

\section{Sintesis CA}

Serbuk $\alpha$-selulosa direaksikan dengan asam asetat glasial selama 3 jam. Proses pretreatment ini bertujuan untuk melemahkan gaya intramolekul dan intramolekul berupa ikatan hidrogen yang cukup kuat pada rantai lignoselulosa. Pelemahan ikatan hidrogen oleh pelarut asam didasarkan oleh adanya sifat protik hidrofilik dari pelarut yang digunakan. Ion $\mathrm{H}^{+}$ bertindak sebagai proton yang akan menyerang ikatan pada struktur selulosa, sehingga melemahkan ikatan hidrogen (Lismeri, 2016).

Selanjutnya proses asetilasi dilakukan dengan menggunakan asam asetat anhidrit dan asam sulfat pekat. Pada penelitian ini dilakukan variasi suhu dan waktu reaksi, di mana eksperimen 1 (Suhu $25{ }^{\circ} \mathrm{C}$; 2,5 jam) dan eksperimen 2 (40 ${ }^{\circ} \mathrm{C} ; 5$ jam $)$. Setelah itu, dihidrolisis menggunakan akuades dan asam asetat glasial Campuran dicuci dengan akuades hingga netral, lalu direndam dalam metanol. Hasil yang diperoleh disaring dan dikeringkan, kemudian digerus menjadi serbuk. Diperoleh serbuk putih CA seperti pada Gambar 1.

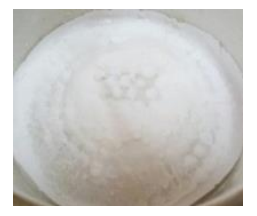

Gambar 1. CA hasil sintesis

Salah satu cara analisis kualitatif untuk mengetahui keberhasilan dari reaksi asetilasi adalah dengan mengidentifikasi perubahan gugus fungsi setelah penambahan gugus asetil. 
Identifikasi gugus fungsi dengan spektrometer FTIR ditunjukkan pada Gambar 2.

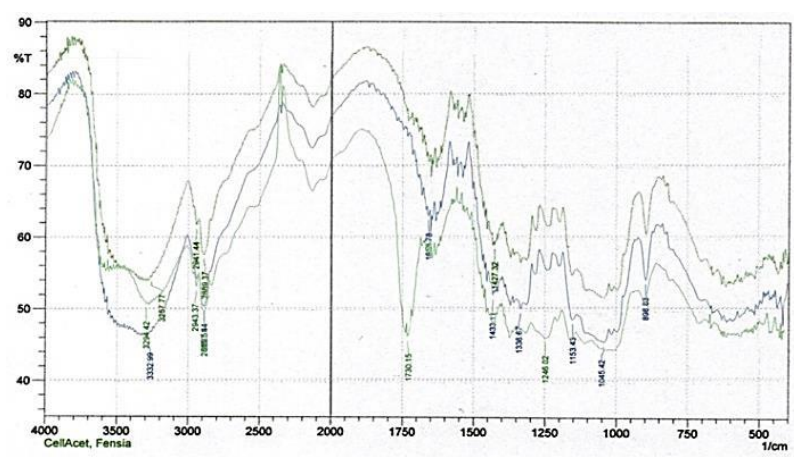

Gambar 2. Spektra FTIR selulosa dan CA

Secara garis besar, spektra FTIR CA hasil eksperimen 1 menunjukkan serapan yang sama dengan spektra IR $\alpha$-selulosa. Hal ini mengindikasikan bahwa reaksi esterifikasi pada proses sintesis belum berjalan dengan baik pada suhu $25{ }^{\circ} \mathrm{C}$ selama 2,5 jam. Serapan melebar pada bilangan gelombang 3257-3375 $\mathrm{cm}^{-1}$ merupakan karakterisitik gugus hidroksi $(-\mathrm{OH})$ dari selulosa yang belum tersubstitusi oleh gugus asetil. Oleh karena itu, dilakukan sintesis CA pada suhu $40{ }^{\circ} \mathrm{C}$ selama 5 jam.

Tabel 2 Perbandingan hasil analisis spektra FTIR selulosa hasil isolasi dengan yang dilaporkan oleh Gaol, dkk. (2013)

\begin{tabular}{cccc}
\hline \multicolumn{3}{c}{ Bilangan Gelombang $\left.\mathbf{( c m}^{-\mathbf{1}}\right)$} & \\
\cline { 1 - 2 } $\begin{array}{c}\text { Eksperimen } \\
\mathbf{1}\end{array}$ & $\begin{array}{c}\text { Eksperimen } \\
\mathbf{2}\end{array}$ & $\begin{array}{c}\text { Gaol, dkk. } \\
\mathbf{( 2 0 1 3 )}\end{array}$ & Keterangan \\
\hline & & & $-\mathrm{OH}$ \\
3257 & 3294 & 3400 & $\mathrm{C}_{\mathrm{sp}} 3^{-}$ \\
2941 & 2943 & 2950 & Hasimetrik \\
2889 & 2885 & 2860 & $\mathrm{C}_{\mathrm{sp}}-\mathrm{H}$ \\
- & 1730 & 1750 & simetrik \\
1242 & 1246 & 1235 & $\mathrm{C}=\mathrm{O}$ ester \\
& & & $-\mathrm{C}-\mathrm{O}$ asetil \\
\hline
\end{tabular}

Berdasarkan hasil analisis, terlihat perbedaan yang signifikan pada spektra FTIR CA hasil eksperimen 2. Intensitas serapan gugus hidroksi $(-\mathrm{OH})$ menurun sedangkan serapan gugus asetil meningkat. Adanya serapan pada bilangan gelombang $1730 \mathrm{~cm}^{-1}$ yang merupakan karakteristik dari gugus karbonil $(-\mathrm{C}=\mathrm{O})$ ester. Hal ini menunjukkan bahwa secara kualitatif selulosa telah mengalami reaksi esterifikasi, sehingga produk CA telah terbentuk. Perbandingan hasil analisis spektra FTIR CA hasil sintesis dengan yang dilaporkan oleh Gaol, dkk. (2013) disajikan pada Tabel 2. Untuk membuktikan telah terjadi reaksi esterifikasi terhadap selulosa secara kuantitatif, dilakukan penentuan kadar asetil dan DS terhadap CA hasil eksperimen 1 dan 2.

\section{Penentuan kadar asetil dan DS}

Analisis kadar asetil bertujuan untuk mengetahui jenis selulosa asetat yang dihasilkan termasuk monoasetat, diasetat, atau triasetat. Penentuan kadar asetil didasarkan pada reaksi saponifikasi, yaitu reaksi antara basa dan ester asetat membentuk sabun dan asam asetat (Fessenden dan Fessenden, 1999). Pengaruh kondisi reaksi asetilasi terhadap kadar asetil dan DS CA hasil sintesis disajikan pada Tabel 3.

Tabel 3 Kadar asetil dan DS selulosa asetat

\begin{tabular}{ccccccc}
\multicolumn{7}{c}{ hasil sintesis } \\
\hline \multirow{2}{*}{ No } & $\begin{array}{c}\text { Suhu } \\
\left({ }^{\circ} \mathbf{C}\right)\end{array}$ & $\begin{array}{c}\text { Waktu } \\
(\mathbf{j a m})\end{array}$ & $\begin{array}{c}\text { CA } \\
(\mathbf{g})\end{array}$ & $\begin{array}{c}\text { Kadar air } \\
(\boldsymbol{\%})\end{array}$ & $\begin{array}{c}\text { Kadar asetil } \\
(\boldsymbol{\%})\end{array}$ & \multirow{2}{*}{ DS } \\
\hline 1 & 25 & 2,5 & 2,34 & 93,22 & 28,413 & 1,482 \\
2 & 40 & 5 & 1,64 & 91,11 & 38,207 & 2,295 \\
\hline
\end{tabular}

Data di atas menunjukkan bahwa DS CA meningkat dengan bertambahnya waktu dan suhu reaksi, namun jumlah $\mathrm{CA}$ yang dihasilkan berkurang. Hal ini disebabkan karena pada suhu yang tinggi mulai terbentuk gel. Kadar asetil berbanding lurus dengan DS. Meningkatnya DS selulosa asetat akan meningkatkan titik lelehnya. Titik leleh dari selulosa asetat adalah 170$240{ }^{\circ} \mathrm{C}$.

Selulosa asetat dengan DS 0-2,0 dan kandungan asetil 13-18,6\% tergolong dalam selulosa monoasetat, selulosa diasetat memiliki DS 2,0-2,8 dengan kandungan asetil 35-43,5\%, sedangkan selulosa triasetat memiliki DS 2,8-3,5 dan kandungan asetil 43,5-44,8\%. Berdasarkan nilai DS, maka jenis selulosa yang dihasilkan yaitu monoasetat dan diasetat. Selulosa mono asetat digunakan dalam pembuatan plastik dan cat leker, sedangkan selulosa diasetat dimanfaatkan dalam pembuatan benang dan film fotografi (Fengel dan Wegener, 1995).

\section{Penentuan kelarutan CA}

Selulosa asetat hasil sintesis tidak larut dalam air dan kloroform, tapi sedikit larut dalam etanol dan aseton. 
Fensia A. Souhoka dkk. / Indo. J. Chem. Res., 2018, 5(2), 58-62

\section{KESIMPULAN}

Berdasarkan hasil penelitian dan pembahasan, maka dapat ditarik kesimpulasn sebagai berikut:

1. Selulosa asetat (CA) dapat disintesis melalui reaksi esterifikasi $\alpha$-selulosa menggunakan asam asetat glasial, asam asetat anhidrida dan asam sulfat pekat. Diperoleh DS CA 1,482 (suhu $25^{\circ} \mathrm{C}$, waktu 2,5 jam) dan 2,295 (suhu $40{ }^{\circ} \mathrm{C}$, waktu 5 jam).

2. Karakterisasi CA hasil sintesis yaitu kadar air $(0,322$ dan $0,3111 \%)$, kadar asetil $(28,413$ dan 38,207\%), indentifikasi gugus fungsi dengan FTIR diperoleh serapan pada bilangan gelombang 3257-3375 $\mathrm{cm}^{-1}(-\mathrm{OH}), 1730 \mathrm{~cm}^{-1}$ $\mathrm{C}=\mathrm{O}$ (ester), 1242-1246 $\mathrm{cm}^{-1}$ (C-O asetil). Selulosa asetat hasil sintesis tidak larut dalam air dan kloroform, tapi sedikit larut dalam etanol dan aseton.

\section{DAFTAR PUSTAKA}

Fessenden, R. J., dan Fessenden, J. S., 1999, Kimia Organik, diterjemahkan oleh Pudjaatmaka, A. H., Jilid 2, edisi ketiga, Penerbit Erlangga, Jakarta.
Fengel, D. dan Wegener, G., 1995, Kayu: Kimia, Ultrastruktur, Reaksi-reaksi, edisi Indonesia, diterjemahkan oleh Hardjono Sastrohamidjojo, Univeritas Gadjah Mada Press, Yogyakarta.

Gaol, M. R. L. L., Sitorus, R., Yanthi, S., Surya, I., dan Manurung, R., 2013, Pembuatan Selulosa Asetat dari $\alpha$-Selulosa Tandan Kosong Kelapa Sawit, Jurnal Teknik Kimia, USU, 2 (3), 33-39.

Kamel, S., Ali, N., Jahangir K., Shah, S. M., ElGendyA. A., 2008, Pharmaceutical significance of cellulose: A review. Express Polymer Letters, 2(11), 758-778.

Lismeri, L., Zari, P. M., Novarani, T., dan Darni, Y., 2016, Sintesis Selulosa Asetat dari Limbah Batang Ubi Kayu. Jurnal Rekayasa Kimia dan Lingkungan, 11(2), 82-91.

Souhoka, F. A., 2013, Metilasi Green Selulosa Menggunakan Dimetil Karbonat (DMC) dengan Teknik Sonokimia dan Gelombang Mikro, Tesis, Jurusan Kimia FMIPA Universitas Gadjah Mada, Yogyakarta. 